\title{
A Half-Truth is Not the Whole Truth: The AHA Position on Saturated Fat
}

\author{
Fabian M. Dayrit*
}

Department of Chemistry, School of Science and Engineering, Loyola Schools, Ateneo de Manila University, Katipunan Ave., Loyola Heights, Quezon City 1108

This article was written in response to the advisory published by the American Heart Association (AHA) warning the public against the use of coconut oil due to its saturated fat content (Sacks FM, Lichtenstein AH, Wu JHY, Appel LJ, Creager MA, Kris-Etherton PM, et al. Dietary Fats and Cardiovascular Disease: A Presidential Advisory From the American Heart Association. Circulation. 2017;136(3):e1--e23.).

This article was first published in the websites of the Asian Pacific Coconut Community (www.apccsec.org) and the Integrated Chemists of the Philippines (www.icp.org.ph). Dr. Fabian Dayrit is also the chairman of the Scientific Advisory Committee for Health of the Asian and Pacific Coconut Community and the president of the Integrated Chemists of the Philippines.

\begin{abstract}
This second in this series of papers will present the biases in the American Heart Association's 2017 Presidential Advisory with respect to saturated fat. Although important differences in the metabolic properties of specific SFA have been known since the 1960s, the AHA still considers all SFA as one group having the same properties. There is abundant research available that supports the designation of C6 to C12 fatty acids as medium-chain fatty acids (MCFA). This is particularly relevant to coconut oil, which is made up of about $65 \%$ MCFA. Ignoring the evidence, AHA simply labels coconut oil as SFA. The AHA promotes half-truths, not the whole truth.
\end{abstract}

Abbreviations: AHA: American Heart Association; CHD: coronary heart disease; CVD: cardiovascular disease; HDL: high-density lipoprotein; LCFA: long-chain fatty acid; LDL: low-density lipoprotein; MCFA: medium-chain fatty acid; MCT: medium-chain triglyceride; oxLDL: oxidized low-density lipoprotein; PUFA: polyunsaturated fatty acid; oxLDL: oxidized low-density lipoprotein; SFA: saturated fatty acid

\section{INTRODUCTION}

On June 16, 2017, the American Heart Association issued its AHA Presidential Advisory which repeated its recommendation to "shift from saturated to unsaturated fats" (Sacks et al., 2017). While this advisory did not present any new data, it provided a re-analysis of old data which selectively rejected some studies which it claims did not satisfy "rigorous criteria for causality," while reinforcing those which were favorable to its conclusions.

The first paper in this series (Dayrit, 2017) showed that the scientific basis upon which the AHA made its recommendations is flawed and the Dietary Guidelines for Americans, which has been recommending a low-saturated fat diet for 35 years, has made Americans obese even as heart disease - 
the supposed concern of the AHA - has remained the top health problem.

This second article will focus on "saturated fatty acids," the fat that AHA wants us to minimize. This article will analyze the 2017 AHA Presidential Advisory and provide counter evidence from the scientific literature, including clinical studies, to show that much of the confusion that we have today regarding the role of these fats in a healthy diet stems from the selective use of scientific information regarding saturated fat. The 2017 AHA Presidential Advisory provided only half the truth on saturated fat.

\section{SFA, MCFA AND LCFA}

Saturated fatty acids (SFAs) generally refer to the following linear carboxylic acids: caproic $\left(\mathrm{C}_{5} \mathrm{H}_{11} \mathrm{CO}_{2} \mathrm{H}, \mathrm{C} 6\right)$, caprylic $\left(\mathrm{C}_{7} \mathrm{H}_{15} \mathrm{CO}_{2} \mathrm{H}, \mathrm{C} 8\right)$, capric $\left(\mathrm{C}_{9} \mathrm{H}_{19} \mathrm{CO}_{2} \mathrm{H}, \mathrm{C} 10\right)$, lauric $\left(\mathrm{C}_{11} \mathrm{H}_{23} \mathrm{CO}_{2} \mathrm{H}\right.$, C12), myristic $\left(\mathrm{C}_{13} \mathrm{H}_{27} \mathrm{CO}_{2} \mathrm{H}, \mathrm{C} 14\right)$, palmitic $\left(\mathrm{C}_{15} \mathrm{H}_{31} \mathrm{CO}_{2} \mathrm{H}, \mathrm{C16}: 0\right)$, and stearic $\left(\mathrm{C}_{17} \mathrm{H}_{35} \mathrm{CO}_{2} \mathrm{H}\right.$; C18:0). SFAs share the same structural features, but differ in their molecular size. Figure 1 shows their chemical structure and their \% composition in coconut oil. Because of the apparent similarity in their chemical structures, SFAs are often assumed to possess the same biochemical and physiological properties. This is not true.

Coconut oil is an important chemical feedstock for the oleochemical industry*. It is hydrolyzed and separated into its individual fatty acids. Lauric acid (C12), the main component of coconut oil, has the highest commercial value and is used in the manufacture of various surfactants. There was a need to find applications for the other fatty acids. In the 1960s, a new synthetic group of fats was developed - "medium-chain triglyceride" (MCT) which was made up mainly of C8 and C10. This commercial mixture was later called "MCT oil" and the main component fatty acids, C8 and C10, were called "medium-chain fatty acids" (MCFA). Initial feeding studies on rats showed that MCT oil was non-toxic and did not lead to weight gain compared with lard (Senior, 1968). Human clinical trials later showed that MCT oil was useful for patients with lipid disorders and for weight loss and it became commercially available in the mid-1960s (Harkins \& Sarett, 1968). Since then, MCT oil has been widely used in clinical practice as a special dietary oil and has been classified by the US FDA as GRAS (generally recognized as safe) (FDA, 2012). Because of its wide commercial availability and safety, medical researchers use MCT oil in their research. Consequently, most medical researchers consider MCFA to include C8 and C10 only; by exclusion, they use the term "long-chain" fatty acids (LCFA) to mean the longer SFAs, C12 and longer.

*The oleochemical industry uses fatty acids from vegetable and animal fats for various applications, such as polymers, surfactants, paints, coatings, engine lubricants, and others.

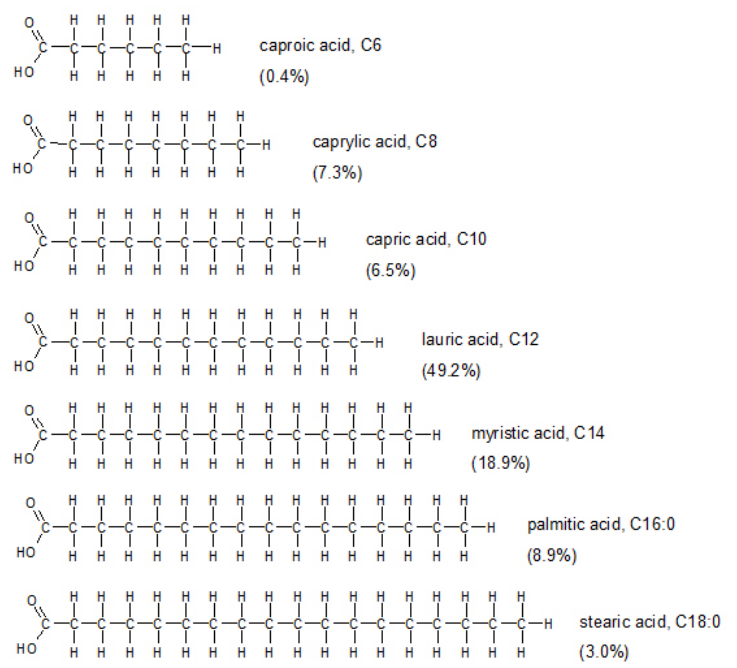

Figure 1. Chemical Structure of Saturated Fatty Acids and Their \% Composition in Coconut Oil (Codex, 2015).

This historical account clearly shows that the classification of MCFA as C8 and C10 was based on the commercial availability of MCT oil and not on scientific considerations, and its wide use in clinical research reinforced this. However, based on biochemical and physiological properties, the classification of MCFA should include the fatty acids from $\mathrm{C} 6$ to $\mathrm{C} 12 .{ }^{* *}$

**It is relevant to mention here that commercial products with a composition that includes C6 to C12 are now available for special dietary purposes, such as a ketone diet (see later).

Numerous researchers consider MCFAs to include the fatty acids from C6 to $\mathrm{C} 12$ based on their metabolic properties (Bach \& Babayan, 1982; St. Onge \& Jones, 2002; McCarty \& DiNicolantonio, 2016; Schonfeld \& Wojtczak, 2016; TMIC, 2017). MCFAs possess special properties that differentiate them from LCFAs. This section will highlight some of the special characteristics of MCFAs in general, and C12 in particular, will show why using only the single category of "saturated fatty acid" is a half-truth.

\section{SFAS IN VARIOUS FATS AND OILS}

All biological organisms and cells utilize different fatty acids to produce lipids that are characteristic 
of the organism and cell type to fulfill its structural or functional requirements. The fatty acid profiles of the various vegetable oils are characteristic of the plant source (Codex, 2015). Coconut oil has a characteristic fatty acid profile that differs from other vegetable oils in terms of its fatty acid profile: almost $50 \%$ is C12, about $65 \%$ is $\mathrm{C} 6$ to $\mathrm{C} 12$, and $92 \%$ is saturated. In contrast, the fatty acid profiles of all other vegetable oils start mainly with C16 and contain a significant proportion of unsaturated fatty acids. For example, soybean oil and corn oil both contain over 50\% C18:2 (linoleic acid, an omega-6 fatty acid) and over $80 \%$ total unsaturated fat. Even animal fats, such as beef fat and lard, contain a substantial amount of unsaturated fat. For example, both beef fat and lard contain about 60\% total unsaturated fatty acids even though these are often referred to as "saturated fat". Clearly, the fatty acid composition of coconut oil is very different from those of animal fats, including butter (Figure 2).

Another feature that sets the group of MCFAs (C6 to $\mathrm{C} 12$ ) apart is that they are not generally present in human abdominal fat and liver fat, and they are not constituents of serum lipids, whether as triglycerides or phospholipids. Analysis of fats in the liver using mass spectral imaging analysis did not detect any MCFA; the smallest fatty acid found was C14 (Debois et al., 2009). This is consistent with the claims that MCFAs (C6 to C12) comprise a separate category from LCFA and that the use of "SFA" as a common label for this group is incomplete.

Another distinguishing characteristic of the group of MCFA (C6 to C12) is that they are rarely found attached to cholesterol as fatty acid ester derivatives. Plasma cholesterol is attached to long chain saturated and unsaturated fatty acid esters, in particular C16:0, C18:0, C18:1, C18:2, and C20:4 (AOCS, 2014). That is, LCFA and PUFA are involved with the circulation of cholesterol around the blood stream and cholesterol deposited in arterial plaques, not MCFA.

\section{METABOLIC PROPERTIES OF SFAS}

The metabolic properties of the various SFAs clearly show differences between MCFA and LCFA. Here, we describe three major steps: first, lipase hydrolysis to release the free fatty acid; second, transport of the free fatty acid across the membrane to enter the cell; and third, mitochondrial oxidation to produce energy.

The first step involves the release of fatty acids from the triglyceride, a process called hydrolysis. In a study of various triglycerides using rat pancreatic lipase, C12 was found to be released most rapidly, followed by C4 (butyrate) (Mattson \& Volpenhein, 1969).
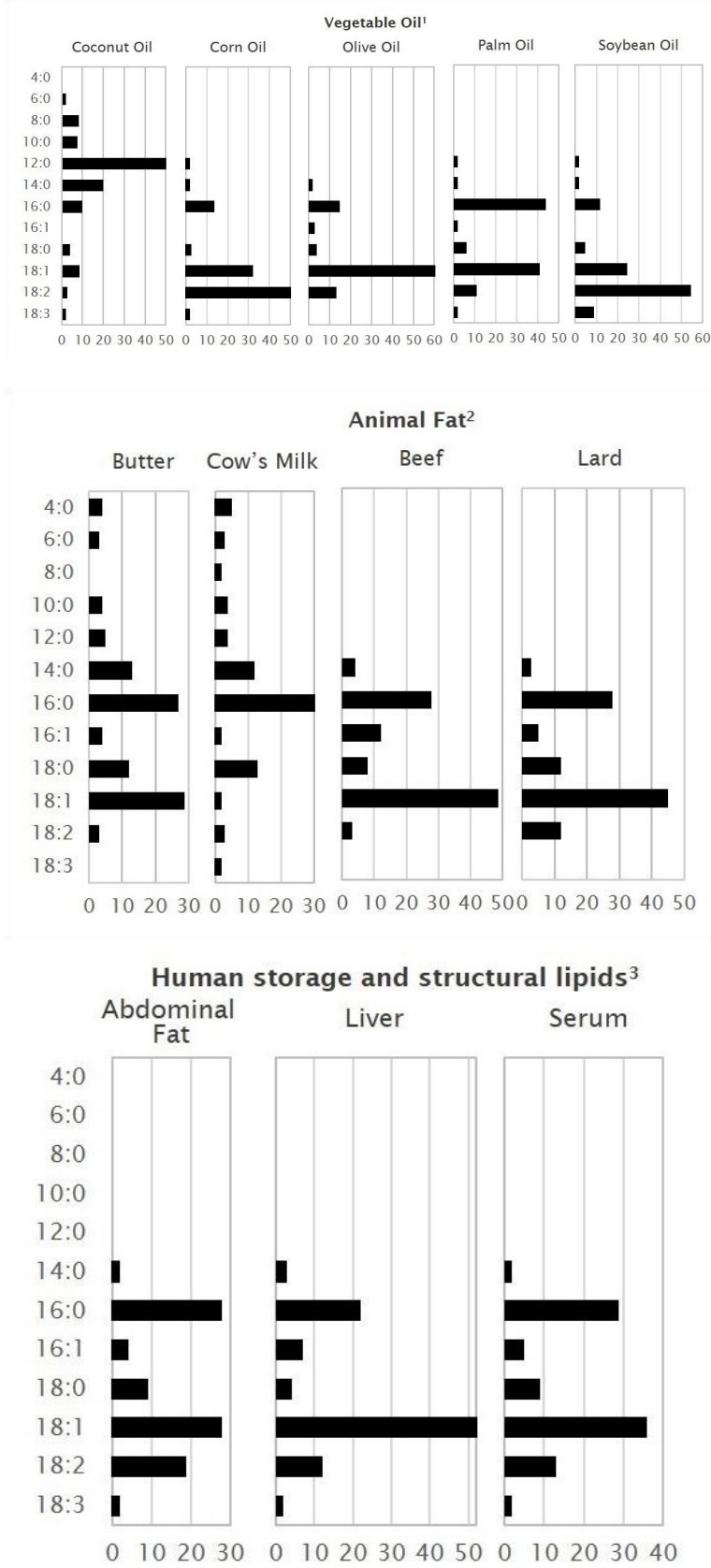

Figure 2. Fatty Acid Composition of Various Lipids: Vegetable Oils, Animal Fat, and Human Storage and Structural Lipids (' Codex 2013, 2015; ${ }^{2}$ Gunstone, 1996; Mansson, 2008; ${ }^{3}$ Kotronen et al., 2010).

The second limiting step in the metabolism of SFAs is the rate at which it can cross the membranes of cells where they can be metabolized. MCFA can cross the membrane rapidly while LCFA and PUFA require carnitine (Bremer, 1983; Schafer et al., 1997; Hamilton, 1998). The third step is fatty acid oxidation. In human liver mitochondria, C12 is more rapidly and completely oxidized compared with C18 (DeLany et al., 2000). This is one reason why coconut oil is not fattening and is better for metabolic energy than other vegetable oils. 
Thus, a detailed accounting of the steps in the metabolism of SFAs shows that their properties and behavior are not the same. MCFA (C6 to C12) are clearly different from LCFA (C14 and longer).

\section{KETOGENESIS}

Ketogenesis refers to the production of ketone bodies (KBs) - beta-hydroxybutyrate (BHB), acetoacetate (Acac) and acetone - from the metabolism of fat mainly in the liver. Ketone bodies are energyrich molecules that are released by the liver into circulation to be used by other tissues and organs, such as the heart, brain and muscles (Krebs, 1970; Liu, 2008). This is the basis for the ketogenic diet.

There are three ways of inducing ketogenesis: first, by ingestion of MCFAs; second, by taking a very high-fat diet (greater than $80 \%$ ) using on a longchain vegetable oil, such as corn oil or soybean oil (Akkaoui 2009); and third, by fasting.

Upon ingestion and entering the small intestine, fatty acids are channeled either to the portal vein going directly to the liver, or are repackaged into other lipid bodies (called chylomicrons) to enter the bloodstream. MCFAs pass directly through the portal vein to the liver where they are converted into ketone bodies. Thus, MCFAs provide the most convenient and rapid way of producing ketone bodies. LCFAs and PUFAs are packaged into chylomicrons and are bound to cholesterol and circulate around the bloodstream after which they are deposited in the liver (Bach \& Babayan, 1982).

\section{THE UNIQUE PROPERTIES OF C12}

C12 has special properties that are not shared even by other MCFAs: its distribution in the small intestine is variable; and it has strong antimicrobial properties.

Distribution in Intestine. C12 is unique because its distribution between the portal vein and lymphatic system depends on the feeding condition (You et al., 2008). Under normal conditions, most of the C12 is channeled to the portal vein. However, a concentrated injection of $\mathrm{C} 12$ has been shown to distribute about half to the portal vein and half to the lymphatic system (Sigalet et al., 1997). Ingestion of $\mathrm{C} 12$ together with proteins may direct more C12 to the lymphatic system (Schonfeld \& Wojtczak, 2016) (Figure 3). This special behavior of C12 was foretold as early as the 1950s, when some researchers suggested the additional categories of "intermediatechain fatty acids" (Schon et al., 1955; Goransson, 1965; Knox et al., 2000), and "transition fatty acid" (You et al., 2008).

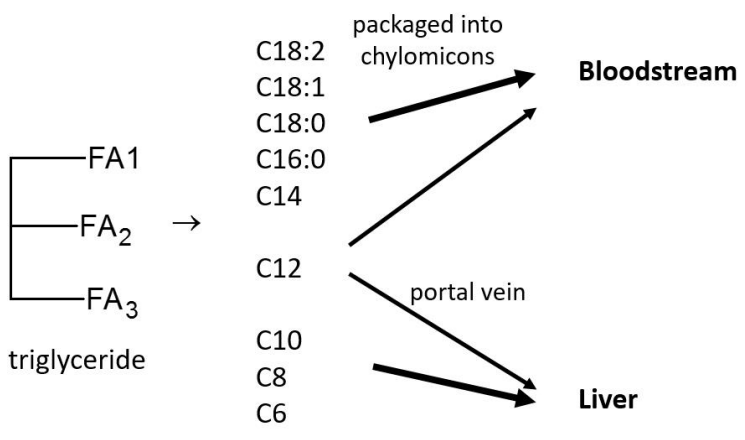

free fatty acids

Figure 3. Hydrolysis of Triglycerides and Distribution of Various Fatty Acids between the Portal Vein and Bloodstream. Depending on the dietary condition, C12 can be distributed to both in varying amounts.

Antimicrobial Properties. $\mathrm{C} 12$ is recognized as the most effective antimicrobial fatty acid. C12 and its monoglyceride, monolaurin, have significant antimicrobial activity against gram positive bacteria and a number of fungi and viruses. Considering its antimicrobial property, it is an important property that some C12 can enter the bloodstream to provide antimicrobial protection. Because $\mathrm{C} 12$ and monolaurin are non-toxic and inexpensive, many food and cosmetic products use these compounds as antimicrobial agents. Interestingly, some antimicrobial natural products have been discovered that have a $\mathrm{C} 12$ group attached. Other MCFAs, $\mathrm{C} 8$ and $\mathrm{C} 10$, have limited antimicrobial activity; LCFAs have very little, if any, antimicrobial activity (Dayrit, 2015).

To summarize the discussion thus far: MCFA (C6 to C12) have very different biochemical and physiological properties from LCFA (C14 to C18). However, not once did the 2017 AHA Presidential Advisory refer to the existence of MCFA and LCFA and simply used the general category of SFA. This is not scientifically justifiable, and for a scientific society like the AHA, this is inexcusable.

\section{"SATURATED FAT" AND "ANIMAL FAT" IN THE SCIENTIFIC LITERATURE}

The vast majority of epidemiological studies, starting from Ancel Keys (1957) to the present, have failed to distinguish MCFA and LCFA and make their conclusions using the gross category of SFA. Unlike PUFAs, which are differentiated as omega- 6 and omega-3, most epidemiologists, except those who study coconut oil in the diet, ignore the differences between MCFA and LCFA. In fact, most doctors and nutritionists commit the error of lumping animal fats and coconut oil into one category. Is it any wonder then that the wrong dietary advice has been made for coconut oil and C12? 
There are, however, a few papers that have specifically addressed C12. In 2003, Mensink and co-workers combined the results of 60 controlled trials into a single analysis (called a meta-analysis) and calculated the effects of the amount and type of fat on the ratio of total cholesterol to HDL (high-density lipoprotein), as well as to lipids. They reported that $\mathrm{C} 12$ increased HDL so that the net effect was to decrease the ratio of total cholesterol to HDL, a beneficial result. On the other hand, the LCFAs C14 and C16:0 had little effect on the ratio, while C18:0 reduced the ratio slightly. This is certainly a favorable result for $\mathrm{C} 12$.

Interestingly, the 2017 AHA Presidential Advisory also disposed of the beneficial properties of HDL without adequate proof, proclaiming that now CHD would be all about LDL: "...changes in HDLcholesterol caused by diet or drug treatments can no longer be directly linked to changes in CVD, and therefore, the LDL-cholesterol-raising effect should be considered on its own."

Since HDL is generally considered a standard lipid indicator, it is incumbent upon the AHA to provide definitive evidence to support its claim that HDL is now useless as a predictor of CHD.

Today, several types of LDL particles are known. LDL particles can be small and dense LDL (sdLDL) or large and buoyant (lbLDL). sdLDL is more susceptible to oxidation producing oxidized LDL (oxLDL). Thus sdLDL is more atherogenic and has been shown to be a strong predictor of $\mathrm{CHD}$, while large buoyant LDL is not (Toft-Petersen et al., 2011; Hoogeveen et al., 2014).

In a 10-year study in Finland on 1,250 subjects, the various types of lipoproteins - LDL, HDL, and oxLDL - were measured. The study concluded that oxLDL, in proportion to LDL and HDL, was a strong risk factor of all-cause mortality independent of confounding factors (Linna et al., 2012). Furthermore, it has also been reported that the ratio of triglyceride to HDL is also a predictor for coronary disease (da Luz et al., 2008). If this is the case, HDL should remain an important lipid parameter, contrary to the AHA proclamation.

In the case of LDL, the absence of data on sdLDL and oxLDL in early studies involving LDL measurements makes their conclusions questionable. Correlations which have been made between LDL and CHD cannot therefore be considered reliable.

\section{CONCLUSION}

The warnings against saturated fat started with
Ancel Keys. Keys never showed any appreciation for the physiologic differences between mediumchain fat and long-chain fat. The AHA has adopted this position to ignore the distinction between MCFA and LCFA despite numerous advances in their science. Detailed comparison of the fatty acid composition shows that coconut oil is very different from animal fat and studies that assume that they are similar are therefore in error. These may be one of the reasons why the Dietary Guidelines have not worked.

To this conclusion, we can apply the warning that Benjamin Franklin once made:

$$
\text { "Half a truth is often a great lie." }
$$

\section{REFERENCES}

[AOCS] American Oil Chemists' Society Lipid Library (2014). Sterols 1. Cholesterol and Cholesterol Esters. (http://lipidlibrary.aocs.org/Primer/content. cfm?ItemNumber=39303, downloaded June 9, 2017.)

Akkaoui M, Cohen I, Esnous C, Lenoir V, Sournac M, Girard J (2009). Modulation of the hepatic malonyl-CoA-carnitine palmitoyltransferase $1 \mathrm{~A}$ partnership creates a metabolic switch allowing oxidation of de novo fatty acids. Biochem J. 420: 429-438

Bach AC, Babayan VK (1982). Medium-chain triglycerides: an update. Am J Clin Nutr. 36:950962.

Bremer J (1983). Carnitine-Metabolism and Functions. Physiol Rev. 63(4):1420-1466.

[Codex] Codex Alimentarius 210-1999, amended 2015, FAO.

da Luz PL, Favarato D, Faria-Neto Jr, Lemos P; Chagas ACP (2008). High ratio of triglycerides to HDL cholesterol ratio predicts extensive coronary disease. Clinics. 63:427-32.

Dayrit FM (2015). The Properties of Lauric Acid and their Significance in Coconut Oil. J Am Oil Chem. Soc. 92:1-15.

Dayrit FM (2017). The Warning on Saturated Fat: From Defective Experiments to Defective Guidelines. https://www.apccsec.org/apccsec/ apccsec-home.html.

Delany JP, Windhauser MM, Champagne CM, Bray GA (2000). Differential oxidation of individual 
dietary fatty acids in humans. Am J Clin Nutr. 72(4):905-911.

Debois D, Bralet M-P, Le Naour F, Brunelle XA, Laprevote O (2009). In Situ Lipidomic Analysis of Nonalcoholic Fatty Liver by Cluster TOF-SIMS Imaging. Anal Chem. 81:2823-2831.

[FDA] Food and Drug Administration. 2012. GRAS Notice (GRN) No. 449. http://www. fda.gov/Food/FoodIngredients Packaging/ GenerallyRecognizedasSafeGRAS/GRASListings/ default.htm

Goransson G (1965). The Metabolism of Fatty Acids in the Rat. VIII. Lauric Acid and Myristic Acid. Acta Physiol Scand. 64: 383-386.

Gunstone, F (1996). Fatty Acid and Lipid Chemistry. Blackie: London.

Hamilton JA (1998). Fatty acid transport: difficult or easy? J. Lipid Res. 39:467-481.

Harkins RW, Sarett HP (1968). Medium-Chain Triglycerides. J Am Med Assoc. 203(4):272-274.

Hoogeveen RC, Gaubatz JW, Sun W, Dodge RC, Crosby JR, Jiang J, Couper D, Virani SS, Kathiresan S, Boerwinkle E, Ballantyne CM (2014). Small Dense Low-Density Lipoprotein-Cholesterol Concentrations Predict Risk for Coronary Heart Disease. Arterioscler Thromb Vasc Biol. 34:10691077

Keys A (1957). Epidemiologic aspects of coronary artery disease. J Chron Dis. 6(5): 552-559.

Knox E, VanderJagt DJ, Shatima D, Huang YS, Chuang LT, Glew RH (2000). Nutritional status and intermediate chain-length fatty acids influence the conservation of essential fatty acids in the milk of northern Nigerian women. Prostaglandins Leukot Essent Fatty Acids 63(4):195-202.

Kotronen A, Seppänen-Laakso T, Westerbacka J, Kiviluoto T, Arola J, Ruskeepää A-L, Yki-Järvinen H, Orešič M (2010). Comparison of Lipid and Fatty Acid Composition of the Liver, Subcutaneous and Intra-abdominal Adipose Tissue, and Serum. Obesity 18:937-944.

Krebs HA, Hems R (1970). Fatty Acid Metabolism in the Perfused Rat Liver. Biochem J. 119: 525-533.

Linna M, Ahotupa M, Lopponen MK, Irjala K, Vasankari T (2012). Circulating oxidised LDL lipids, when proportioned to HDL-c, emerged as a risk factor of all-cause mortality in a populationbased survival study. Age and Ageing 0: 1-4.

Liu YC (2008). Medium-chain triglyceride (MCT) ketogenic therapy. Epilepsia 49(Suppl. 8):33-36.

Mansson HL (2008). Fatty acids in bovine milk fat. Food \& Nutrition Research 2008. DOI: 10.3402/ fnr.v52i0.1821.

Mattson FH, Volpenhein RA (1969). Relative rates of hydrolysis by rat pancreatic lipase of esters of C2C18 fatty acids with C1-C18 primary n-alcohols. J. Lipid Res. 10:271-276.

McCarty MF, James J DiNicolantonio JJ (2016). Lauric acid-rich medium-chain triglycerides can substitute for other oils in cooking applications and may have limited pathogenicity. Open Heart 3:e000467. doi:10.1136/openhrt-2016-000467.

Mensink RP, Zock PL, Kester ADM, Katan MB (2003). Effects of dietary fatty acids and carbohydrates on the ratio of serum total to HDLcholesterol and on serum lipids and apolipoproteins: a meta-analysis of 60 controlled trials. Am J Clin Nutr. 77:1146-1155.

Sacks FM, Lichtenstein AH, Wu JHY, Appel LJ, Creager MA, Kris-Etherton PM, Miller M, Rimm EB, Rudel LL, Robinson JG, Stone NJ, Van Horn LV (2017). Dietary Fats and Cardiovascular Disease, A Presidential Advisory From the American Heart Association. Circulation. 2017;135: e1-e24.

Schon H, Gey F, Strecker FJ, Weitzel G (1955). Metabolic studies with fatty acids of intermediate chain length. III. Feeding experiments with lauric acid esters. Hoppe Seylers Z Physiol Chem. 301(3):143-155.

Schonfeld P, Wojtczak L (2016). Short- and medium-chain fatty acids in the energy metabolism - the cellular perspective. J Lipid Res. 57: 943-954.

Senior JR (editor). 1968. Medium Chain Triglycerides, Univ. of Pennsylvania Press., cited in: Sulkers EJ, The use of medium-chain triglycerides in preterm infants. Thesis, Erasmus University Rotterdam, 1993. ISBN 90-9006053-7

Sigalet DL, Winkelaar GB, Smith LJ (1997). Determination of the route of medium-chain and long-chain fatty acid absorption by direct measurement in the rat. JPEN J Parenter Enteral Nutr. 21(5):275-278.

[TMIC] The Metabolomics Innovation Center 
(2017). Metabocard for Dodecanoic acid. Canadian Institutes of Health Research, Alberta Innovates Health Solutions, and The Metabolomics Innovation Centre (TMIC). http://www.hmdb.ca/metabolites/ HMDB00638 (downloaded: June 11, 2017).

Toft-Petersen AP, Tilsted HH, Aarøe J, Rasmussen K, Christensen T, Griffin BA, Aardestrup IV, Andreasen A, Schmidt EB (2011). Small dense LDL particles a predictor of coronary artery disease evaluated by invasive and CT-based techniques: a case-control study. Lipids in Health and Disease 2011, 10:21. http://www.lipidworld.com/content/10/1/21.

You YQN, Ling PR, Qu JZ, Bistrian BR (2008). Effects of Medium-Chain Triglycerides, Long-Chain Triglycerides, or 2-Monododecanoin on Fatty Acid Composition in the Portal Vein, Intestinal Lymph, and Systemic Circulation in Rats. JPEN J Parenter Enteral Nutr. 32(2): 169-175. 